\title{
ELECTROFORESIS DE LAS PROTEINAS DEL SUERO EN LA GLOMERULONEFRITIS DIFUSA AGUDA
}

\author{
Dr. GABRIEL SILVA
}

\author{
Cátedra de Pediatría del Prof. Arturo Bazza Goñi. \\ Hospital "Manuel Atriarán". Santiago.
}

Varios son los autores que se han interesado en investigar las proteínas plasmáticas en las Nefropatías ${ }^{1} 3_{-}{ }_{-} x_{-}$. Entre ellos, el síndrome nefrósico y la amiloidosis renal, han preocupado más, porque en estas afecciones, la alteración de las fracciones proteicas y de la proteína total, son conocidas desde hace tiempo.

En cambio, la GNDA ha quedado un poco al margen de estas investigaciones. Jayle y cols.", describen algunos cambios que consideran constantes: discreta baja de albúmina y aumento de las globulinas alfa 2 y gamma. Otros autores --", concluyen que, la baja de la albúmina y el alza de la gamma globulina con proteinemia normal o poco descendida, es algo característico de la nefritis aguda, diferenciándose, de esta manera, del sindrome nefrósico, en que hay notable baja de la proteina sanguínea total, de la albúmina y la gamma globulina que con frecuencia está ausente.

En la Cátedra del Prof. Baeza Goñi y en el Servicio de Niños Mayores icon la colaboración de los Drs. W. Galasso, L. Vera y S. Martínez), nos propusimos estudiar las variaciones de la curva electroforética de las proteinas séricas, a través de la evolución de la enfermedad y buscar alguna posible relación entre estos cambios proteicos y algunos signos y síntomas de la enfermedad.

\section{MÉTODo}

Para ello, sometimos a todos los enfermos que ingresaron con el diagnóstico de GNDA, a un plan común, que consistió en practicar un examen sistemático, y un control periódico de la hipertensión, de los signos de insuficiencia cardíaca, edema y aspecto macroscópico de la orina. Los exámenes de Laboratorio realizados, fueron los de rutina (hemograma, sedimentación, orina, etc.). Las electroforesis se realizaron en tres oportunidades: la primera al ingreso; la segunda, cuando ya los síntomas clínicos estuvieron ausentes (excepto el sindrome urinario); y la tercera, al ser dado de alta, aceptando como signo residual, la presistencia de hematuria. El criterio de alta fué : tiempo de evolución, examen clínico negativo, sedimentación y clearences (urea y creatinina) normales .

El aparato usado para hacer las electroforesis fué el de Elphor-H de la Casa Bender \& Hobein de Münich, Alemania. La tinción se hizo con amino Schwarz. Para la elaboracíón de las electroforesis se contó con la colaboración del Laboratorio de Investigación del Hospital Arriarán (dirigido por el Dr. F. Mönckeberg). Los valores normales usados como control se tomaron de la investigación que, sobre niños normales, se realizó en el mencionado Laboratorio ${ }^{10}$.

\section{RESULTADOS}

En la Tabla N? 1 se anotan los promedios y las DS de la primera, segunda y tercera electroforesis, practicadas a 5,7 ; 20,6 ; y $39,4 \mathrm{ds}$, como promedios de iniciada la enfermedad.

La albúmina estaba baja. La DS, también baja, lo que nos demuestra que este descenso se presenta en forma constante. El relación a los promedios normales, están altas las globulinas Alfa 1, Alfa 2, y gamma, y discretamente descendida, la Beta globulina. Pero, las DS son muy altas, para la beta y gamma glol:ulinas, lo que nos indica que existe una gran disper-

TABLA No I

PROMRDIOS PORCENTUALES DE LAS FRACCIONES PROTEICAS EN 17 ENFIKMMOS DE GNDA. MEDIDAS POR LA TRCNICA ELECTROFORFTICA

\begin{tabular}{|c|c|c|c|c|c|c|c|}
\hline & Prom. & $\mathrm{E}_{\mathbf{D} \mathbf{s}}^{\mathbf{F}}$ & $\begin{array}{r}2^{\circ} . \\
\text { Prom. }\end{array}$ & $\mathbf{F}_{\text {Ds. }}$ & $\begin{array}{r}30 \mathbf{E} \\
\text { Prom. }\end{array}$ & Ps. & $\begin{array}{l}\text { Nor- } \\
\text { msl }\end{array}$ \\
\hline $\begin{array}{l}\text { Albimina } \\
\text { Alfa } 1 \\
\text { Ala } 2 \\
\text { Beta } \\
\text { Gama } \\
\text { Prot. tot. } \\
\text { Prom. ds. }\end{array}$ & $\begin{array}{c}52.8 \\
3.50 \\
14.30 \\
9.10 \\
21.70 \\
6.20 \\
5.7\end{array}$ & $\begin{array}{c}2.64 \\
1.62 \\
3.46 \\
18.25 \\
17.41 \\
0.05\end{array}$ & $\begin{array}{r}57.20 \\
2.17 \\
13.04 \\
21.20 \\
13.45 \\
6.90 \\
20.6\end{array}$ & $\begin{array}{c}36.1 \\
2.06 \\
4.7 \\
10.62 \\
21.51 \\
0.02\end{array}$ & $\begin{array}{c}61.70 \\
1.60 \\
11 . \\
10.21 \\
11 \\
6.50 \\
39.4\end{array}$ & $\begin{array}{c}35.55 \\
1.53 \\
14.30 \\
32.52 \\
6.1 \\
0.00\end{array}$ & $\begin{array}{c}65 \\
2.2 \\
10 \\
11.2 \\
13 \\
7\end{array}$ \\
\hline
\end{tabular}


sión de valores. En cambio, Alfa 2 globulina tiene una DS relativamente haja. La proteinemia total estuvo discretamente descendida con muy escasa dispersión de valores (DS 0.05 ).

Los promedios de la segunda electroforesis muestran una tendencia franca a la normalización. Llama la atención que, si bien, la gamma globulina da un valor muy cercano a lo normal, su DS es enorme (Ds 21,51 ).

La proteinemia total fué normal.

La tercera electroforesis, da valores promedios prácticamente normales, con DS, de las observaciones, muy alta.

Se buscó alguma relación entre las variaciones de la gamma globulina y la existencia de insuíciencia cardíaca ( 8 casos). hematuria residual ( $\bar{y}$ casos) y amigdalitis crónica ( $\overline{0}$ casos). No se encontró relación con las dos primeras: fué semejante el número gue en la segunda y tercera electroforesis que daban valores normales, altos o bajos. En cambio, en ninguno de los casos con amigdalitis crónica. se normalizó la gamma globulina. De los cinco casos, en cuatro persistió alta (fluctuando entre 14 y 18 ; ) y en uno estuvo ausente.

Los dos casos, cuya nefritis fué secundaria a un púrpura anafiláctico, tuvieron curvas electroforéticas semejantes a las observadas en el síndrome nefrósico, pero con proteinemias normales: uno de ellos, que egresó en buenas condiciones, tenía Alfa 2 y Beta globulinas muy altas $(24.25 \%$ y $27.80 \%)$ y ausencia de gamma globulina en Ios dos primeros exámenes y sólo en el último (al mes de evolución) reaparecieron, aunque con un valor mínimo $(6 \%)$. El otro caso, que egresó con hematuria residual, y en el que persiste después de cuatro meses de control, tuvo en un primer examen una curva en todo semejante a la nefritis aguda, pero en los dos que continuaron la gamma globulina no aparece y alfa 2 y beta estaban muy altas. La albúmina mostró franca tendencia a descender. También, como en el caso anterior, la proteinemia total fué normal. (Tabla No 2).

\section{COMENTARIO}

Las variaciones de las fracciones proteicas del suero, estudiadas por la electroforesis en papel, nos muestra cambios característicos y sensiblemente constantes, al iniciarse la GNDA. Estos consisten
TABLA No 2

SEFRITIS SECUNDARIA A PURPURA ANAFILACTICO: EVOLUCION ELECTROFORETICA DE LAS PROTEINAS DFL SUERO

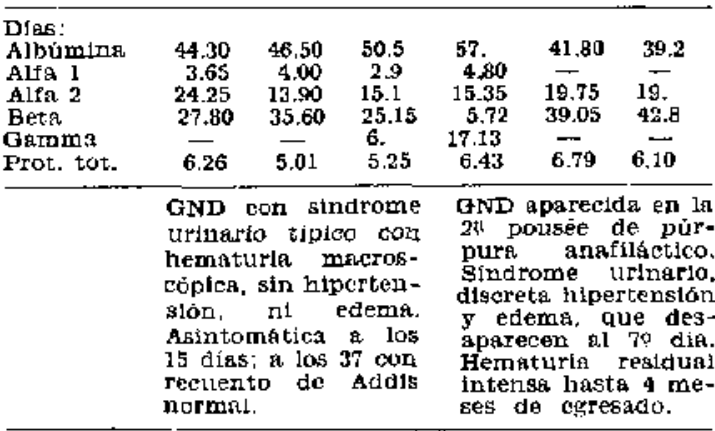

en baja de la albúmina, ascenso de alfa 2 y gamma globulina. Estos hallazgos, como ya otros autores lo habian hecho notar, la hacen diferir mucho de la curva observada en el síndrome nefrósico ${ }^{\text {f_z_s; }}$; sólo es común de ambas el ascenso de alfa 2 globulina. La fracción beta dió resultados muy variables, con un promedio bajo. Con el método de Tiselius esta fracción fué encontrada alta, tanto en nefritis como en nefrosis $1 . *$; pero, con el micrométodo, los autores no se han puesto de acuerdo en cuanto a la magnitud de beta globulina y ésto, como se desprende de nuestras observaciones, se debería a la gran dispersión de valores con que se presenta.

A medida que los sintomas desaparecen, los promedios de las distintas fracciones se van normalizando. en el momento de darlos de alta, estos valores son prácticamente normales. Pero éstos, pierden gran parte de su valor, como indice para apreciar la evolución de la enfermedad, por las enormes dispersiones que sufren.

En los cinco casos en que coexistió una amigdalitis crónica, la gamma globulina no se normalizó. Este hecho, del cual es dificil sacar conclusiones, sugeriría que esta infección crónica tiende a mantener alta la gamma globulina, lo que estarja de acuerdo con lo que se produce en otras infecciones crónicas activadas.

En el único de nuestros enfermos en que se encontró desnutrición clínica, ésta no influyó sobre las variaciones cuantitativas de las fracciones proteicas.

En los dos casos cuya nefritis se vinculó a un púrpura anafiláctico, las curvas electroljoreticas fueron semejantes a la 
del sindrome nefrósico. Podría esto relacionarse con una posible evolución subaguda o subcrónica de la afección; más aún, si recordamos el mal pronóstico que es habitual observar en estos enfermos.

\section{CONCLUSIONES}

1 \% En la GNDA existiria una curva electroforética de las proteínas del suero, más o menos constante, al iniciarse la enfermedad. Esta se caratcerizaría por: baja de la albúmina $(x=52.8$ ) $\mathrm{y}$ de beta globulina $(x=9.10)$ y alza de las alfa 1 $(\mathrm{x}=3.5)$, alfa $2(\mathrm{x}=14.30)$ y gamma $(x=21.70)$ globulinas. La proteinemia total desciende discretamente.

$2^{\circ}$ Los promedios a los 20 días de evoIución, muestran una franca tendencia de las fracciones proteicas a normalizarse, lográndolo a los 40 días.

$3^{\text {a }}$ Las enormes DS de los valores econtrados en nuestras observaciones, tanto al desaparecer los sintomas ( 2 a efectroforesis), como al egreso ( $3^{a}$ electroforesis), hacen perder a los promedios su posible valor de índices de la evolución de la enfermedad.

$4^{\circ}$ En las GNDA con coexistencia de amigdalitis crónica, las gamma globulinas no se normalizaron durante los 40 dias promedio de observación.

$5^{\text {o }}$ En nuestros dos casos de nefritis secundaria a púrpura anafíláctica, las variaciones de la curva electroforética fueron semejantes a las observadas en el síndrome nefrósico, pero con proteinemias normales.

$6^{\circ}$ No se encontró relación entre los cambios cuantitativos de las fracciones proteicas y la existencia de insuficiencia cardiaca y hematuria residual.

\section{RESUMEN}

Se estudian las fracciones proteicas del suero mediante la técnica de electroforesis en papel, en 17 enfermos de GNDA. Se hizo esta determinación al ingreso $\left(5^{\circ}\right.$ día de iniciada la afección) al desaparecer los síntomas clinicos (20 días) y al egreso (40 días). Se concluye, que habria una curva electroforética más o menos constante, al iniciarse la afección, consistiendo sus variaciones más notables en: discreta bipoproteinemia, baja de la albúmina $y$ ascenso de las globulinas alfa $2 \mathrm{y}$ gamma. Durante la evolución, los promedios de estas fracciones llegan a normalizarse, pero presentando gran dispersión de valores, lo que haría, de estos resultados, malos índices de la evolución de la enfermedad.

\section{SUMMARY}

\section{ELECTROPHORESIS OF SERUM PHOTEINS IN ACUTE GLOMERULO NEPHRITIS}

A study is done on serum proteins by means of electrophoresis on paper in 17 cases of acute glomerulo nephritis. This determination was done on entrance $(5 \mathrm{th}$ day of the disease), when clinical symptoms had dissapeared (20th day) and on discharge (40th day). We conclude in the existence of a electrophoretic curve more or less constant at the beginning of the illness consisting its main changes in small hypoproteinemia, low of albumin and ascent of alpha 2 and gamma globulin. During evolution the averace of these fractions arrive to normal, but existing a great scattering of values, which make of these results a bad index in the evolution of the sickness.

\section{BIBLIOGRAFía}

1.-GUNNAR, B. BTICKLAR, F. C. BURKS Y B. F. MC KENZIE. - "Electrophoretic studles of the nephrotic syndrome in chlldren". Proc. of Mayo Clinic $29: 21,1954$.

2-LONOSWORTE, L. G MC INNFG D F - "An Electrophoretle study of Nephrotic Bera and Ury ne". J. Exper, Med. 71 777 , 1940.

3.-BENHAMON P. AMOUOH ' $\mathbf{g}$. CHFMLA. - "L9 valeur semejologique de la globuline alta 2 ", L Presse Medicale 61:82, 1953.

4.-RAYNAUD y Cols. - "Hupopotelnemla estudiad por electrororesis on la Nefrosis lipoidica". Algerie Medical, Agosto 1953

5.-M. F, JAYLE, G. LAGNE y G. BOUSBIER, - "Perturbations des protétnes plasmatiques au cours des nephropathtes". Presse Medical 62:61, 1954.

6-R MONTFRO - "La electroforesi's cuantitativa en Medictra". Revista Chllena de Pedjatria, 26:2. 1955 .

7.-G. LAGRDE: - "I.glbumjsurie des nephroses et des nephrjtis'. La Revue du Praticlen, 6:5, 1956 .

8.-R. RAYNAUD y Cols. - "Estudto de veinte casos de sindrome nefróslca estudlados por la electroforests en papel't, Bull. Acad. Nac, Méd. 118:7, 1954,

9.-R. RAYNAUD y Cols. - "Electrotoresis sobre papel en 108 cindromes netrosteos". La nem. de Hopitesux $73: 20,1954$

10.-DORA TVANOVIC. - "Fstudio de les gllcoproteinas séricas par la electroforesis en papel". Memorla de Prueba, 1055.

11.-"Comportamtento de la protelnemia en la GNDa y subaguda". Annali Italiant di Pedistria, $7: 11,1954$. 